\title{
Pengembangan Arsitektur Model Proses Bisnis Pada Pondok Pesantren
}

\author{
Eka Puji Rahayu Lestari'1, Hagar Prily Titania², Anis Shiva 'Ulia Dewi³ ${ }^{3}$ Muhammad Ainul \\ Yaqin 4 \\ Jurusan Teknik Informatika, Fakultas Sains dan Teknologi \\ Universitas Islam Negeri Maulana Malik Ibrahim Malang \\ Jalan Gajayana No. 50 Malang 651544 Telp. +62 (341) 551-354 \\ 116650011@student.uin-malang.ac.id, ${ }^{2} 16650031 @$ student.uin-malang.ac.id, \\ 316650035@student.uin-malang.ac.id, ‘yaqinov@ti.uin-malang.ac.id
}

\begin{abstract}
Islamic boarding school is a religious education institution that teaches and practices Islamic religious education therein. Modeling of Islamic boarding school business processes is a clear and structured description of the flow of activities/business processes in every action that will be taken on activities in boarding schools. Data analysis uses the Porter Value Chain technique to identify the division of main business processes and supporting business processes, while the technique in modeling business processes is to use BPMN (Business Process Modeling \& Notation) based on SOP (Standard Operating Procedure) of each existing business process/activity. The final results obtained from this research are in the form of an architecture of the business process model of Islamic boarding school that can be used as a reference in conducting every business process/activity in Islamic boarding school. So that with this business process architecture model, the implementation of activities can be structured and run in accordance with the expected goals, and can improve the quality of Islamic boarding schools.
\end{abstract}

Keywords: BPMN, Business Process Model, Islamic Boarding School, Porter Value Chain, and Business Process.

Pondok pesantren merupakan lembaga pendidikan keagamaan yang mengajarkan serta mengamalkan pendidikan ilmu agama Islam didalamnya. Pemodelan proses bisnis pondok pesantren adalah penggambaran alur pelaksanaan kegiatan/proses bisnis yang jelas dan terstruktur dalam setiap tindakan yang akan diambil pada kegiatan yang ada di pondok pesantren. Analisis data menggunakan teknik Porter Value Chain untuk mengidentifikasi pembagian proses bisnis utama dan proses bisnis pendukung, sedangkan teknik dalam pemodelan proses bisnis yaitu menggunakan BPMN (Business Process Modelling \& Notation) berdasarkan SOP (Standar Operasional Prosedur) dari setiap proses bisnis/kegiatan yang ada. Hasil akhir yang diperoleh dari penelitian ini yaitu berupa arsitektur model proses bisnis dari pondok pesantren yang dapat digunakan sebagai acuan dalam melakukan setiap proses bisnis/kegiatan dalam pondok pesantren. Sehingga dengan adanya arsitektur model proses bisnis ini, pelaksanaan kegiatan dapat terstruktur dan berjalan sesuai dengan tujuan yang diharapkan, serta dapat meningkatkan kualitas dari pondok pesantren.

Kata kunci: BPMN, Model Proses Bisnis, Pondok Pesantren, Porter Value Chain, dan Proses Bisnis.

\section{PENDAHULUAN}

Pondok pesantren ditinjau dari struktur organisasi memiliki banyak bidang yang menangani kegiatan seperti pengelolaan program akademik, pengelolaan sumber daya manusia, pengelolaan keuangan, dan pengelolaan sarana dan prasarana. Setiap kegiatan-kegiatan tersebut masuk dalam satu arsitektur bisnis dalam pondok pesantren. Secara umum arsitektur bisnis menggambarkan kumpulan aktivitas bisnis, data dan informasi yang ada dalam lingkungan internal 
dan eksternal organisasi. Arsitektur bisnis adalah representasi formal dan tools serta informasi bagi profesional bisnis organisasi dalam menilai, merubah, dan merancang bisnis [1]. Arsitektur bisnis juga menunjukkan relasi atau hubungan antara: aktivitas, kemampuan, fungsi, proses, waktu, urutan proses, sumber daya, orang, ketergantungan, kebutuhan, kolaborasi, organisasi, lokasi, batasan, data, sistem, peralatan, biaya, kontrol, keputusan, rules, keputusan, alur bisnis, aktivitas manual \& otomatis, transaksi, perbedaan, dan kemungkinan.

Dalam arsitektur bisnis terdapat alur/prosedur dilaksanakannya setiap kegiatan yang disebut proses bisnis. Proses bisnis adalah sebuah kumpulan aktivitas yang dijalankan secara koordinasi didalam lingkungan organisasional dan lingkungan teknis. Aktivitas-aktivitas ini bersama-sama mencapai tujuan bisnis. Setiap proses bisnis ditetapkan oleh satu organisasi (bagian), namun dapat berinteraksi dengan proses yang dijalankan organisasi (bagian) lain [2].Proses bisnis dapat dibagi menjadi dua yaitu proses utama dan proses pendukung. Proses utama, yaitu proses yang menghasilkan nilai bagi perusahaan. Mereka yang langsung berhubungan dengan perusahaan dan menerima suplai dari pemasok untuk kegiatan pelanggan dan proses pendukung, bukan proses yang secara langsung menghasilkan nilai, melainkan sebuah proses yang mendukung berlangsungnya proses utama [3].

Setiap proses bisnis dibuatlah pemodelan proses bisnis untuk penggambaran dengan detail setiap alur/prosedur kegiatan.Model proses bisnis merepresentasikan struktur dan perilaku proses bisnis yang dilakukan dalam suatu organisasi. Analisis terhadap struktur dan perilaku proses bisnis dapat dilakukan untuk perbaikan, penyesuaian, pertumbuhan, dan peningkatan proses bisnis. Model proses bisnis mempunyai skala untuk menggambarkan seberapa banyak dan seberapa kompleks aktifitasnya [4].

Penelitian sebelumnya yang dilakukan oleh Yuni R. et.al yaitu "Arsitektur Bisnis: Pemodelan Proses Bisnis dengan Object Oriented" menjelaskan tentang pemodelan proses bisnis dengan object penelitian yaitu pada perguruan tinggi [5]. Pada penelitian ini dibuat pemodelan proses bisnis dengan object penelitian pada pondok pesantren dengan acuan pada 52 standar minimum pondok pesantren yang diadaptasi dari standar minimum pondok pesantren yang dibuat oleh Welsh Assembly Government Kementrian Kesehatan dan Pelayanan Sosial pada tahun 2003. Dalam pondok pesantren terdapat banyak kegiatan/aktivitas yang dilakukan didalamnya, tetapi pondok pesantren tidak memiliki prosedur pelaksanaan kegiatan yang baik. Sehingga kegiatan yang terdapat di dalam pondok pesantren tidak terlaksana dengan efektif dan tidak berjalan dengan terstruktur. Sehingga hal ini menjadikan pondok pesantren tidak dapat mencapai banyak tujuan yang diharapkan.

Berdasarkan permasalahan diatas, maka dibuat arsitektur model proses bisnis untuk pondok pesantren yang bertujuan untuk menggambarkan proses bisnis yang lengkap dan jelas dalam setiap tindakan pada kegiatan, dan dapat menjadi acuan dalam melakukan proses kegiatan. Sehingga dengan adanya arsitektur model proses bisnis ini diharapkan dapat menciptakan proses bisnis yang baik, juga dapat meningkatkan kualitas dari pondok pesantren, dan 
menjadikan kegiatan pondok pesantren lebih terstruktur. Pengembangan arsitektur model proses bisnis di pondok pesantren juga sangat diperlukan untuk menggambarkan aktivitas, data, dan informasi apa saja yang ada di dalam pondok pesantren. Dari arsitektur model proses bisnis juga dapat dilihat hubungan antar aktivitas/kegiatan yang ada dalam pondok pesantren.

\section{METODOLOGI PENELITIAN}

\subsection{Pengumpulan Data}

Pada dasarnya kegunaan data (setelah diolah dan dianalisis) adalah sebagai dasar yang objektif didalam proses pembuatan keputusan-keputusan ataupun kebijaksanaan-kebijaksanaan dalam rangka untuk memecahkan persoalan oleh pengambil keputusan [7]. Sumber data dalam penelitian ini menggunakan sumber data primer dan sekunder. Data primer yang digunakan yaitu berupa alur atau prosedur proses bisnis yang ada pada pondok pesantren secara global [6], sebagai berikut:

1. Seleksi Calon Santri Baru

2. Her Registrasi Santri Baru

3. Penentuan Kurikulum

4. Penyusunan Jadwal Pelajaran

5. Jurnal Mengajar

6. Presensi Belajar Santri

7. Ujian Santri

8. Pembagian Kamar Santri

9. Perizinan Santri

10. Pemberlakuan Aturan dan Pemberian Sanksi

11. Penanganan Kebersihan dan Keindahan

12. Pengadaan Kesehatan

13. Alumni

14. Publikasi

15. Kegiatan Rutinan

16. Pengadan Kegiatan

17. Pengelolaan Inventaris

18. Rapat

19. Unit Usaha

20. Keuangan

21. Kepegawaian

22. Pengadaan dan Pemeliharaan Teknologi Informasi

23. Pengadaan Sarana dan Prasarana

Data sekunder yang digunakan dalam penelitian ini berupa 52 standar minimum pondok pesantren yang diadaptasi dari standar minimum pondok pesantren dibuat oleh Welsh Assembly Government Kementrian Kesehatan dan Pelayanan Sosial pada tahun 2003 sebagai acuan dalam pelaksanaan proses bisnis pada pondok pesantren. Berikut merupakanpengelompokkan 52 standar minimum pondok pesantren: 
1. Prosedur dan Kebijakan Kesejahteraan, yaitu:
a) Pernyataan dan praktik pondok pesantren
b) Melawan bullying
c) Perlindungan anak, respon pada tuduhan/penyalahgunaan
d) Perilaku disiplin, hukuman, penghargaan dan pembatasan
e) Respon pada keluhan
f) Pendidikan kesehatan
g) Catatan kesehatan santri

2. Organisasi dan Manajemen, yaitu:
a) Kepemimpinan yang jelas
b) Manajemen krisis
c) Organisasi asrama
d) Aktifitas dan waktu bebas
e) Mengamankan pandangan santri
f) Prefek
g) Staf dan dukungan pihak luar pada santri

3. Dukungan Kesejahteraan Santri, yaitu:
a) Pertolongan pertama dan perawatan medis
i) Akses orang dewasa pada santri dan akomodasinya
b) Perawatan pada santri yang sakit
c) Manajemen kesehatan dan masalah personal
d) Kesamaan kesempatan dan diskriminasi
e) Telepon dan kontak dengan orang tua
f) Perawatan hak milik dan uang saku santri
g) Penerimaan dan pengenalan santri baru

h) Wali pendidikan
i) Pemantauan catatan (monitoring of records)
j) Katering

k) Makanan ringan dan air minun

1) Tindakan pencegahan dan latihan kebakaran

m) Beban wajib santri

n) Akomodasi anak-anak dibandingkan santri lain

o) Penilaian risiko dan aktifitas berisiko tinggi

p) Akses pada informasi dan fasilitas pondok pesantren

4. Staffing, yaitu:

a) Pengawasan santri

b) Pengawasan santri diluar pondok pesantren

c) Pengawasan santri di malam hari

d) Deskripsi kerja, pengenalan, pengawasan, dan pelatihan staf

e) Pedoman pelaksanaan praktik staf

f) Hubungan staf dengan santri

g) Privasi

h) Rekrutmen staf dan pemeriksaan orang dewasa lainnya

5. Premis
a) Akomodasi
pondok pesantren
b) Keamanan dan akses pada akomodasi
c) Tempat tidur
d) Aturan pembelajaran
e) Aturan toilet dan mencuci
f) Mengganti fasilitas dan ruang ganti
g) Area rekreasi
h) Penilaian risiko dan pengamanan bahaya
i) Akomodasi untuk santri yang sakit
j) Laundry 

k) Barang-barang pribadi dan alat tulis
l) Pemondokan (lodgings)
m) Akomodasi dan pertukaran di luar lokasi pondok pesantren

\subsection{Analisis Data}

Analisis data dalam penelitian ini yaitu identifikasi atau pengelompokkan proses bisnis global yang terdapat pada pondok pesantren. Teknik yang digunakan dalam identifikasi proses bisnis yaitu menggunakan teknik Porter Value Chain. Pada Porter value chain proses bisnis global dibagi menjadi dua tipe aktivitas bisnis, yaitu aktivitas bisnis utama dan aktivitas bisnis pendukung [7]. Berikut merupakan hasil pengelompokkan proses bisnis menggunakan teknik porter value chain:

\begin{tabular}{|c|c|c|c|c|c|}
\hline \multicolumn{5}{|c|}{$\begin{array}{l}\text { Firm Infrastucture : Manajemen kantor, Manajemen Keuangan, Manajemen } \\
\text { Usaha }\end{array}$} & \multirow{6}{*}{ Profil } \\
\hline \multicolumn{5}{|c|}{ Human resource management : Manajemen Kepegawaian } & \\
\hline \multicolumn{5}{|c|}{ Product and Technology development : Teknologi Pembelajaran } & \\
\hline \multicolumn{5}{|c|}{ Procurement : Pengadaan Sarana dan Prasarana } & \\
\hline $\begin{array}{l}\text { Inbound } \\
\text { Logistic }\end{array}$ & Operations & $\begin{array}{l}\text { Outbound } \\
\text { Logistics }\end{array}$ & $\begin{array}{l}\text { Sales and } \\
\text { Marketing }\end{array}$ & Servicing & \\
\hline $\begin{array}{l}\text { Manajemen } \\
\text { Santri }\end{array}$ & $\begin{array}{l}\text { Manajemen } \\
\text { Kegiatan } \\
\text { Belajar } \\
\text { Mengajar } \\
\text { (KBM) dan } \\
\text { Manajemen } \\
\text { Kepesantrenan }\end{array}$ & $\begin{array}{l}\text { Manajemen } \\
\text { Alumni }\end{array}$ & $\begin{array}{l}\text { Sosialisasi } \\
\text { Pondok }\end{array}$ & $\begin{array}{l}\text { Kegiatan } \\
\text { Rutinan } \\
\text { Pondok }\end{array}$ & \\
\hline
\end{tabular}

Gambar 1. Pengelompokkan Porter Value Chain

Melalui pengelompokkan pada gambar 1, dapat diketahui bahwa proses bisnis utama yaitu meliputi inbound logistic, operations, outbound logistics, sales and marketing, servicing dan proses bisnis pendukung meliputi firm infrastructure, human resource management, product and technology development, procurement. Dari porter value chain didapatkan proses bisnis utama dan proses bisnis pendukung beserta prosedur kegiatan sebagai berikut:

Tabel 1. Prosedur proses bisnis pada porter value chain

\begin{tabular}{|l|l|}
\hline \multicolumn{1}{|c|}{ Proses Bisnis } & \multicolumn{1}{|c|}{ Standar Operasional Prosedur (SOP) } \\
\hline \multicolumn{2}{|c|}{ Proses Bisnis Utama } \\
\hline \multicolumn{2}{|c|}{ Inbound Logistics } \\
\hline Manajemen Santri \\
\hline 1. Pendaftaran Santri Baru & $\begin{array}{l}\text { - Prosedur pendaftaran santri baru secara } \\
\text { online. } \\
\text { - Prosedur pengumpulan persyaratan } \\
\text { pendaftaran. }\end{array}$ \\
\hline 2. Daftar Ulang Santri Baru & $\begin{array}{l}\text { - Prosedur registrasi santri yang dinyatakan } \\
\text { lulus tes. }\end{array}$ \\
\hline \multicolumn{2}{|c|}{ Operations } \\
\hline \multicolumn{2}{|c|}{ Manajemen Kegiatan Belajar Mengajar Diniyah } \\
\hline
\end{tabular}




\begin{tabular}{|c|c|}
\hline 1. Penentuan Kurikulum & - Prosedur penentuan kurikulum. \\
\hline 2. Penyusunan Jadwal Pelajaran & $\begin{array}{l}\text { - Prosedur penetapan jadwal pelajaran selama } \\
\text { satu semester. }\end{array}$ \\
\hline 3. Jurnal Mengajar & $\begin{array}{l}\text { - Prosedur pembuatan jurnal mengajar selama } \\
\text { satu semester. }\end{array}$ \\
\hline 4. Presensi Belajar Santri & - Prosedur pengisian dan aturan absensi santri. \\
\hline 5. Ujian Santri & - Prosedur pelaksanaan ujian santri. \\
\hline \multicolumn{2}{|l|}{ Manajemen Kepesantrenan } \\
\hline 1. Pembagian Kamar Santri & $\begin{array}{l}\text { - Prosedur pembagian kamar dan informasi } \\
\text { tentang pondok pesantren. }\end{array}$ \\
\hline 2. Perizinan Pulang Santri & - Prosedur perizinan dan aturan pulang santri. \\
\hline 3. Pemberian Sanksi Santri & $\begin{array}{l}\text { - Prosedur pemberian sanksi untuk santri yang } \\
\text { melanggar peraturan. }\end{array}$ \\
\hline 4. Penanganan Kesehatan Santri & $\begin{array}{l}\text { - Prosedur penanganan kesehatan santri yang } \\
\text { sakit. }\end{array}$ \\
\hline Proses Bisnis & Standar Operasional Prosedur (SOP) \\
\hline \multicolumn{2}{|c|}{ Outbound Logistics } \\
\hline \multicolumn{2}{|l|}{ Manajemen Alumni } \\
\hline $\begin{array}{l}\text { 1. Pengabdian Alumni Setelah Lulus } \\
\text { Pondok }\end{array}$ & $\begin{array}{l}\text { - Prosedur pengabdian alumni yang sudah } \\
\text { luluspondok. }\end{array}$ \\
\hline \multicolumn{2}{|c|}{ Sales and Marketing } \\
\hline \multicolumn{2}{|l|}{ Sosialisasi Pondok } \\
\hline 1. Publikasi & $\begin{array}{l}\text { - Prosedur sosialisasi, publikasi pondok serta } \\
\text { kegiatan yang ada di pondok ke berbagai } \\
\text { macam media. }\end{array}$ \\
\hline \multicolumn{2}{|r|}{ Servicing } \\
\hline \multicolumn{2}{|l|}{ Kegiatan Rutinan Pondok } \\
\hline 1. Kegiatan Rutinan Mingguan & $\begin{array}{l}\text { - Prosedur persiapan pelaksanaan diba dan } \\
\text { manaqib. }\end{array}$ \\
\hline 2. Kegiatan Rutinan Bulanan & $\begin{array}{l}\text { - Prosedur persiapan pelaksanaan lomba bulan } \\
\text { bahasa. }\end{array}$ \\
\hline 3. Kegiatan Rutinan Tahunan & $\begin{array}{l}\text { - Prosedur persiapan pelaksanaan milad } \\
\text { pondok. }\end{array}$ \\
\hline \multicolumn{2}{|c|}{ Proses Bisnis Pendukung } \\
\hline \multicolumn{2}{|c|}{ Firm Infrastructure } \\
\hline \multicolumn{2}{|l|}{ Manajemen Kantor } \\
\hline 1. Pengadaan Kegiatan & $\begin{array}{l}\text { - Prosedur pembuatan agenda dan jadwal } \\
\text { kegiatan di pondok. }\end{array}$ \\
\hline 2. Pengelolaan Inventaris & $\begin{array}{l}\text { - Prosedur pengelolaan dan pemeriksaan } \\
\text { inventaris pondok secara berkala. }\end{array}$ \\
\hline 3. Rapat Pengurus Pondok & $\begin{array}{l}\text { - Prosedur rapat evaluasi kinerja secara } \\
\text { berkala. }\end{array}$ \\
\hline \multicolumn{2}{|l|}{ Manajemen Keuangan } \\
\hline 1. Keuangan & $\begin{array}{l}\text { - Prosedur pengelolaan pemasukan dan } \\
\text { pengeluaran keuangan pondok. }\end{array}$ \\
\hline \multicolumn{2}{|l|}{ Manajemen Usaha } \\
\hline 1. Koperasi & - Prosedur pengelolaan koperasi pondok. \\
\hline 2. Kantin & - Prosedur pengelolaan kantin pondok. \\
\hline \multicolumn{2}{|c|}{ Human Resource Management } \\
\hline \multicolumn{2}{|l|}{ Manajemen Kepegawaian } \\
\hline 1. Kepegawaian & $\begin{array}{l}\text { - Prosedur penyeleksian, pengawasan, dan } \\
\text { pengelolaan pegawai di pondok. }\end{array}$ \\
\hline Proses Bisnis & Standar Operasional Prosedur (SOP) \\
\hline
\end{tabular}


http://tunasbangsa.ac.id/ejurnal/index.php/jurasik

\begin{tabular}{|l|l|}
\hline \multicolumn{2}{|c|}{ Product and Technology Development } \\
\hline Teknologi Pembelajaran \\
\hline $\begin{array}{l}\text { 1. Pengadaan dan pemeliharaan teknologi } \\
\text { informasi }\end{array}$ & $\begin{array}{l}\text { - Prosedur pengadaan dan pemeliharaan } \\
\text { perangkat Teknologi Informasi di pondok. }\end{array}$ \\
\hline \multicolumn{2}{|c|}{ Procurement } \\
\hline Manajemen Sarana dan Prasarana & $\begin{array}{l}\text { - Prosedur pembuatan peraturan untuk } \\
\text { pengelolaan perpustakaan \& laboratorium. }\end{array}$ \\
\hline $\begin{array}{l}\text { 1. Pengelolaan Perpustakaan dan } \\
\text { Laboratorium }\end{array}$ & $\begin{array}{l}\text { - Prosedur pembuatan peraturan untuk } \\
\text { pengelolaan kamar mandi dan tempat cuci di } \\
\text { pondok. }\end{array}$ \\
\hline $\begin{array}{l}\text { 2. Pengelolaan Kamar Mandi dan Tempat } \\
\text { Cuci }\end{array}$
\end{tabular}

\subsection{Perancangan Model Proses Bisnis}

Perancangan model proses bisnis dalam penelitian ini menggunakan metode Top-Down, yaitu identifikasi dari proses bisnis yang utama atau global sampai ke proses bisnis pendukung. Setiap proses bisnis yang terdapat pada pondok pesantren diperlukan penjelasan detail tentang kejadian-kejadian yang dilakukan mulai awal hingga akhir terjadinya suatu kegiatan agar dapat berjalan dengan terstruktur setiap proses bisnis yang ada. Sehingga dibuatlah standar operasioanl prosedur (SOP) dari setiap proses bisnis tersebut. Standar operasional prosedur digunakan sebagai acuan pembuatan sebuah model proses bisnis pada pondok pesantren dengan menggunakan BPMN (Business Process Modeling Notation).

\section{HASIL DAN PEMBAHASAN}

Hasil dan pembahasan dalam penelitian ini yaitu berupa Arsitektur Model Proses Bisnis Pondok Pesantren secara global yang telah di identifikasi menggunakan porter value chain dan keterkaitan standar minimum pondok pesantren yang di adaptasi dari 52 standar minimum pondok pesantren oleh Welsh Assembly Government Kementrian Kesehatan dan Pelayanan Sosial pada tahun 2003 dengan proses bisnis pondok pesantren global pada porter value chain, serta detail proses bisnis dari setiap proses bisnis global. Gambar 2 merupakan hasil arsitektur model proses bisnis global pondok pesantren.

Berikut arsitektur model proses bisnis global pada pondok pesantren memiliki banyak rincian model proses bisnis dari setiap proses bisnis yang ada. Berikut adalah beberapa rincian model proses bisnis global pada setiap proses bisnis pada pondok pesantren 
Jurnal Riset Sistem Informasi Dan Teknik Informatika (JURASIK)

Volume 5 Nomor 1 Februari, pp 77-88

ISSN: 2527-5771/EISSN: 2549-7839

http://tunasbangsa.ac.id/ejurnal/index.php/jurasik

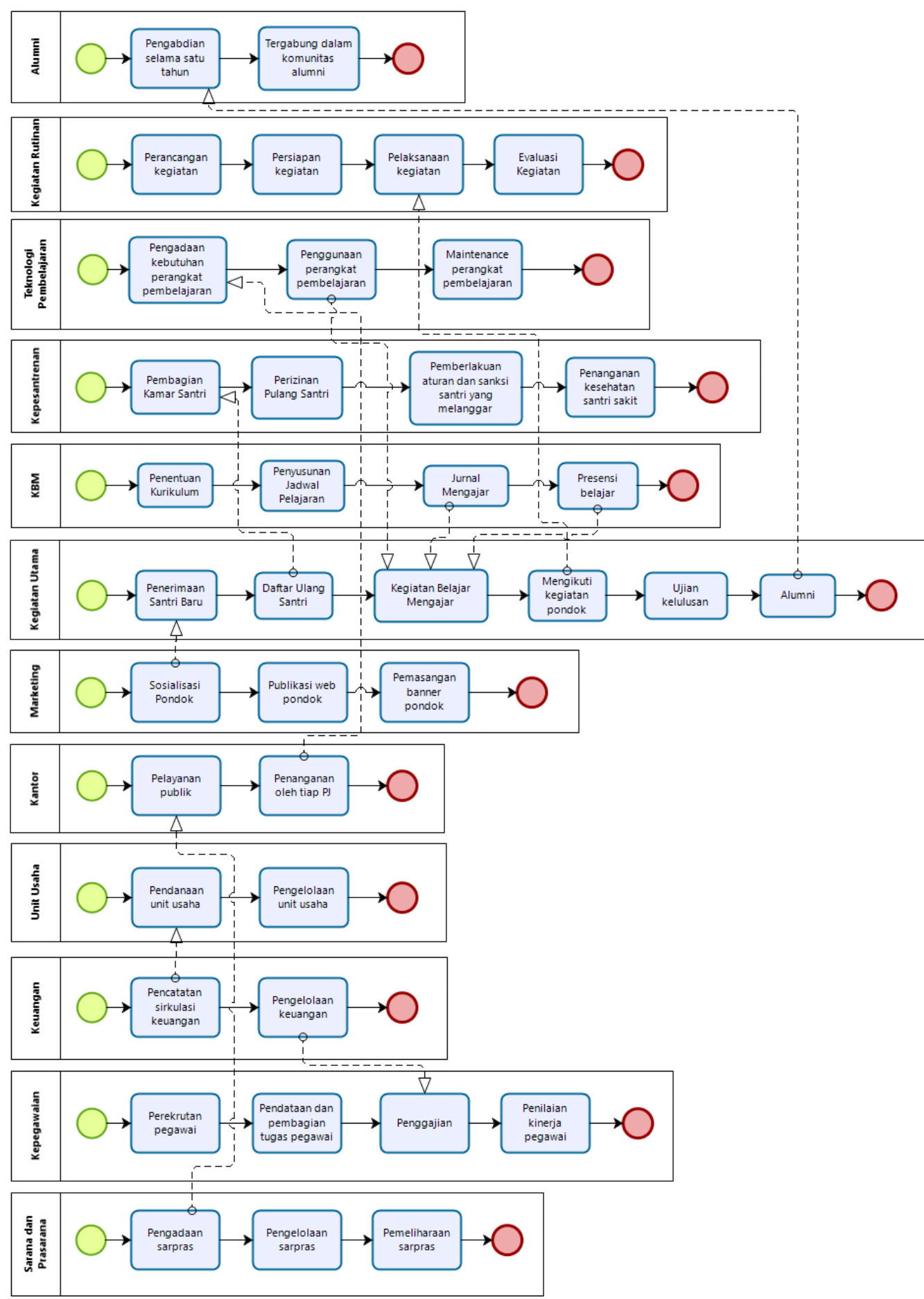

Gambar 2. Model proses bisnis global pondok pesantren

\subsection{Model Proses Bisnis Pendaftaran Santri Baru}

Pada proses bisnis utama inbound logistic terdapat manajemen santri yang didalamnya terdapat proses bisnis pendaftaran santri baru. Berikut adalah standar operasional prosedur (SOP) pendaftaran santri baru : 
a) Calon santri mengisi data pendaftaran online di portal website pondok pesantren.

b) Membayar biaya pendaftaran melalui transfer dan upload bukti pembayaran

c) Calon santri mendapat kartu ujian lewat pemberitahuan email dan dicetak.

d) Calon santri mengumpulkan persyaratan pendaftaran (foto $3 \times 4$, SKKB, Ijazah, Kartu Keluarga, formulir pendaftaran \& surat pernyataan orang tua).

e) Calon santri mengikuti ujian tes dan wawancara.

f) Calon santri dapat melihat pengumuman lulus tes lewat portal website sesuai tanggal yang telah ditentukan.

Dari standar operasional prosedur diatas, dapat dibuat sebuah model proses bisnis seperti gambar 3 berikut :

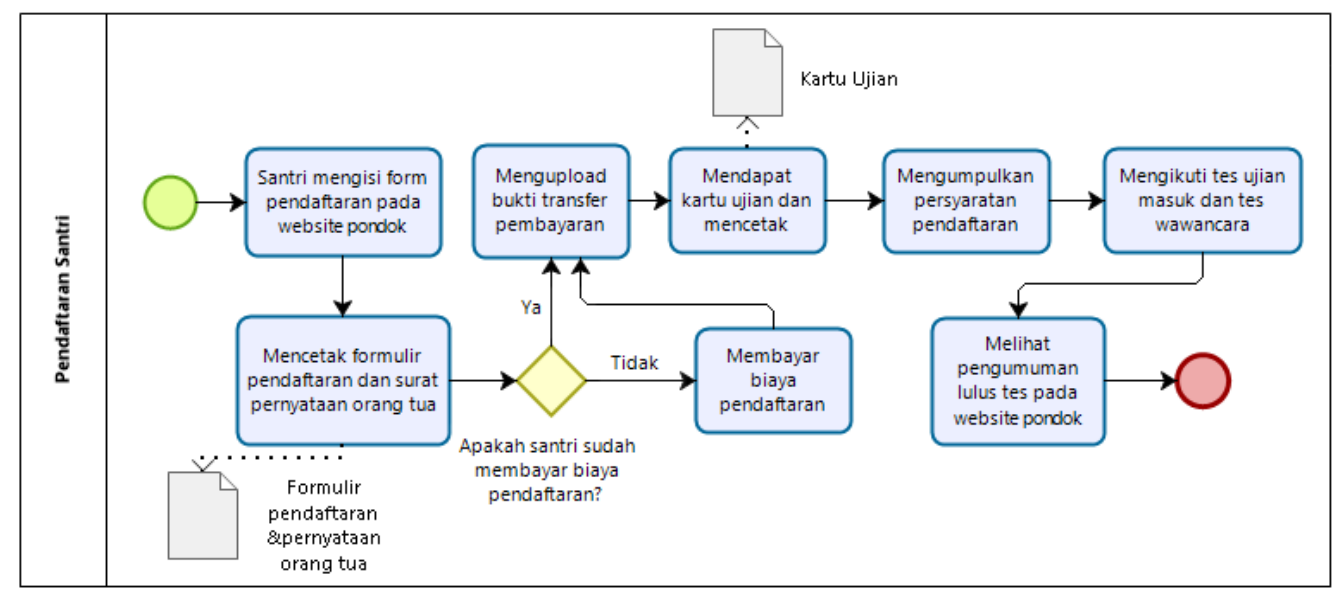

Gambar 3. Model proses bisnis pendaftaran santri baru

\subsection{Model Proses Bisnis Perizinan Pulang Santri}

Pada proses bisnis utama operations terdapat manajemen kepesantrenan yang didalamnya terdapat proses bisnis perizinan pulang santri. Berikut adalah standar operasional prosedur (SOP) perizinan pulangsantri:

a) Santri meminta izin pulang kepada pengurus pondok.

b) Jika pengurus pondok memberikan izin pulang, maka santri akan mendapatkan surat izin pulang.

c) Santri sowan kepada pengasuh pondok.

d) Santri mengisi data perizinan pulang di kantor satpam.

Dari standar operasional prosedur diatas, dapat dibuat sebuah model proses bisnis seperti gambar 4 berikut: 


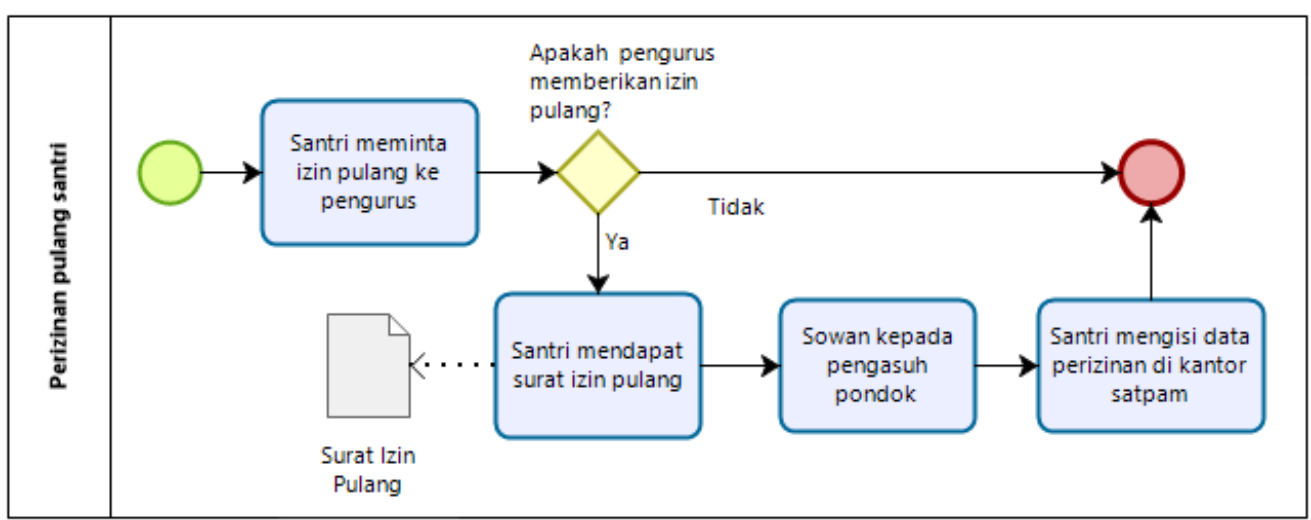

Gambar 4. Model proses bisnis perizinan pulang santri

\subsection{Model Proses Bisnis Penanganan Kesehatan Santri}

Pada proses bisnis utama operations terdapat manajemen kepesantrenan yang didalamnya terdapat proses bisnis penanganan kesehatan santri. Berikut adalah standar operasional prosedur (SOP) penanganan kesehatan santri :

a) Santri menjelaskan keluhan sakit yang dirasakan.

b) Staf kesehatan memberikan penanganan kepada santri dan diberi obat.

c) Jika santri membutuhkan penanganan yang lebih, maka akan dirujuk ke puskesmas terdekat.

d) Santri diberikan penanganan di puskemas dan diberikan obat.

e) Jika santri membutuhkan penanganan lebih, maka dirujuk ke Rumah Sakit dengan persetujuan wali santri.

f) Apabila wali santri tidak menyetujui untuk dirujuk ke Rumah Sakit maka santri akan dijemput pulang oleh wali santri.

Dari standar operasional prosedur diatas, dapat dibuat sebuah model proses bisnis seperti gambar 5 berikut:

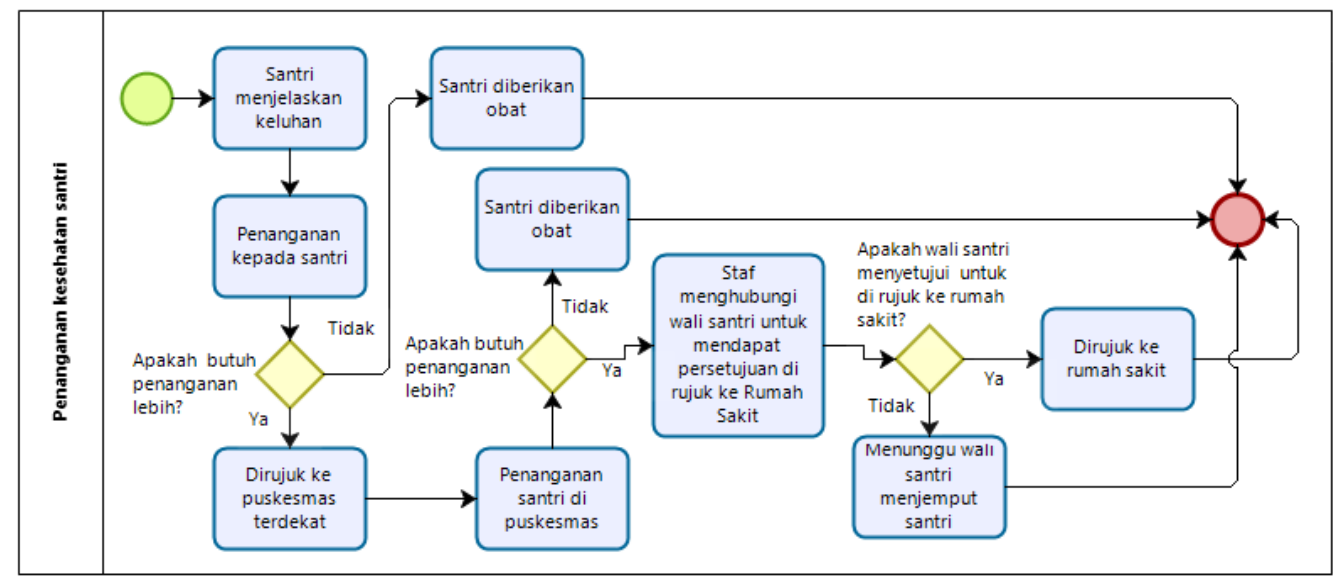

Gambar 5. Model proses bisnis penanganan kesehatan santri

Keterkaitan antara proses bisnis global yang telah diidentitifikasi menggunakan porter value chain dengan standar minimum pondok pesantren yang 
di adaptasi dari 52 standar minimum pondok pesantren oleh Welsh Assembly Government Kementrian Kesehatan dan Pelayanan Sosial pada tahun 2003 dapat dijabarkan sebagai berikut:

Tabel 2. Keterkaitan porter value chain dengan standar minimum pondok pesantren

\begin{tabular}{|c|c|c|}
\hline Porter Value Chain & Standar & Prosedur Pada Standar \\
\hline \multicolumn{3}{|c|}{ Inbound Logistics } \\
\hline \multicolumn{3}{|l|}{ Manajemen Santri } \\
\hline 1. Pendaftaran Santri Baru & $\begin{array}{l}\text { - Standar } 21 \rightarrow \text { Penerimaan dan } \\
\text { Pengenalan Santri Baru. }\end{array}$ & $\begin{array}{l}\text { - Prosedur pengenalan dan } \\
\text { pengasuhan santri }\end{array}$ \\
\hline \multicolumn{3}{|c|}{ Operations } \\
\hline \multicolumn{3}{|l|}{ Manajemen Kepesantrenan } \\
\hline 1. Perizinan Pulang Santri & $\begin{array}{l}\text { - Standar } 30 \rightarrow \text { Akses pada } \\
\text { Informasi dan Fasilitas Pondok } \\
\text { Pesantren }\end{array}$ & $\begin{array}{l}\text { - Prosedur santri yang } \\
\text { meninggalkan pondok } \\
\text { pesantren (ijin keluar } \\
\text { pondok) }\end{array}$ \\
\hline 2. Pemberian Sanksi Santri & $\begin{array}{l}\text { - Standar } 4 \rightarrow \text { Perilaku, Displin, } \\
\text { Hukuman, Penghargaan, dan } \\
\text { Pembatasan. }\end{array}$ & $\begin{array}{l}\text { - Pelaporan pelanggaran } \\
\text { santri } \\
\text { - Rapat untuk memutuskan } \\
\text { hukuman }\end{array}$ \\
\hline $\begin{array}{l}\text { 3. Penanganan Kesehatan } \\
\text { Santri }\end{array}$ & $\begin{array}{l}\text { - Standar } 15 \rightarrow \text { Pertolongan } \\
\text { Pertama dan Perawatan Medis }\end{array}$ & $\begin{array}{l}\text { - Prosedur pertolongan } \\
\text { pertama } \\
\text { - Prosedur rujukan ke } \\
\text { rumah sakit } \\
\text { - Prosedur pendampingan } \\
\text { santri yang dirawat di } \\
\text { rumah sakit } \\
\end{array}$ \\
\hline Porter Value Chain & Standar & Prosedur Pada Standar \\
\hline \multicolumn{3}{|c|}{ Human Resource Management } \\
\hline \multicolumn{3}{|l|}{ Manajemen Kepegawaian } \\
\hline 1. Kepegawaian & $\begin{array}{l}\text { - Standar } 33 \rightarrow \text { Pengawasan Santri } \\
\text { di Malam Hari } \\
\text { - Standar } 34 \rightarrow \text { Deskripsi Kerja, } \\
\text { Pengenalan, Pengawasan, dan } \\
\text { Pelatihan Staf } \\
\text { - Standar } 38 \rightarrow \text { Rekrutmen Staf dan } \\
\text { Pemeriksaan Orang Dewasa } \\
\text { Lainnya }\end{array}$ & $\begin{array}{l}\text { - Prosedur perekrutan staf } \\
\text { - Prosedur pemeriksaan } \\
\text { dan seleksi staf } \\
\text { - Prosedur penugasan dan } \\
\text { deskripsi kerja pada staf } \\
\text { - Prosedur pengawasan di } \\
\text { malam hari } \\
\text { - Penjadwalan piket di } \\
\text { malam hari }\end{array}$ \\
\hline \multicolumn{3}{|c|}{ Procurement } \\
\hline \multicolumn{3}{|c|}{ Manajemen Sarana dan Prasarana } \\
\hline $\begin{array}{l}\text { 1. Pengelolaan Kamar } \\
\text { Mandi dan Tempat Cuci }\end{array}$ & $\begin{array}{l}\text { - Standar } 44 \rightarrow \text { Aturan Toilet dan } \\
\text { Mencuci }\end{array}$ & $\begin{array}{l}\text { - Prosedur penggunaan } \\
\text { toilet } \\
\text { - Prosedur penggunaan } \\
\text { ruang cuci }\end{array}$ \\
\hline
\end{tabular}

\section{SIMPULAN}

Dengan demikian, dapat disimpulkan bahwasanya dalam pondok pesantren terdapat banyak kegiatan/aktivitas yang dilakukan didalamnya, tetapi pondok pesantren tidak memiliki prosedur pelaksanaan kegiatan yang baik.Arsitektur 
bisnis sendiri menggambarkan kumpulan aktivitas bisnis, data dan informasi yang ada dalam lingkungan internal dan eksternal organisasi. Arsitektur bisnis adalah representasi formal dan tools serta informasi bagi profesional bisnis organisasi dalam menilai, merubah, dan merancang bisnis. Dalam arsitektur bisnis terdapat alur/prosedur dilaksanakannya setiap kegiatan yang disebut proses bisnis. Proses bisnis adalah sebuah kumpulan aktivitas yang dijalankan secara koordinasi didalam lingkungan organisasional dan lingkungan teknis.

Maka dari itu dibuatnya arsitektur model proses bisnis untuk pondok pesantren yang bertujuan untuk menggambarkan proses bisnis yang lengkap dan jelas dalam setiap tindakan pada kegiatan, dan dapat menjadi acuan dalam melakukan proses kegiatan. Pengembangan arsitektur model proses bisnis di pondok pesantren juga sangat diperlukan untuk menggambarkan aktivitas, data, dan informasi apa saja yang ada di dalam pondok pesantren.

\section{DAFTAR PUSTAKA}

[1] SOA, "Business Architecture: The Missing Link between Business Strategy and Enterprise Architecture", SOA Consortium Members Present, Object Management Group (OMG), 2010.

[2] Weske, M., "Process Management Concepts, Languages, Architectures", 2nd ed. 2012, Springer, Berlin, 2012.

[3] Andersan, B., "Business Process Improvement Toolbox", 2nd ed, ASQ Quality Press, America, 2007.

[4] Yaqin, M.A., Majid, M., Fradana, F.F. and Mustofa, M.R., "Pertumbuhan Model Proses Bisnis Pada Permainan Hay Day Menggunakan Metode Regresi”, Seminar Nasional Inovasi dan Aplikasi Teknologi di Industri 2019, Malang, 2019.

[5] Yunis, R., Surendro, K. and Telaumbanua, K., "Arsitektur Bisnis: Pemodelan Proses Bisnis dengan Object Oriented", Seminar Nasional Informatika 2010, Yogyakarta, 2010.

[6] Sriminangga, N.P., "Perencanaan Strategis Teknologi Informasi Pada Pondok Pesantren Annur II Al-Murtadlo Malang dengan Metode Wetherbe", Tesis, Program Sarjana Teknik Informatika. UIN Maulana Malik Ibrahim Malang, Malang, 2013.

[7] Ward, J., and Peppard, J., "Strategic Planning for Information Systems", 3th ed, Wiley, England, 2002. 